\title{
Article \\ Study on Ultrasonically-Enhanced Sulfuric Acid Leaching of Nickel from Nickel-Containing Residue
}

\author{
Zhanyong Guo ${ }^{1}$, Ping Guo ${ }^{2}$, Guang $\mathrm{Su}^{1}$ and Fachuang Li ${ }^{1, *}$ \\ 1 Henan Institute of Technology, Xinxiang 453003, China; guozhanyong123@126.com (Z.G.); \\ 13781909400@hait.edu.cn (G.S.) \\ 2 Yunnan Provincial Key Laboratory of Intensification Metallurgy, Kunming 650093, China; gp1230@126.com \\ * Correspondence: 18738373302@hait.edu.cn; Tel.: +86-0373-3691137
}

Citation: Guo, Z.; Guo, P.; Su, G.; Li, F. Study on Ultrasonically-Enhanced Sulfuric Acid Leaching of Nickel from Nickel-Containing Residue. Crystals 2021, 11, 810. https://doi.org/ $10.3390 /$ cryst11070810

Academic Editor: Umberto Prisco

Received: 11 May 2021

Accepted: 10 July 2021

Published: 12 July 2021

Publisher's Note: MDPI stays neutral with regard to jurisdictional claims in published maps and institutional affiliations.

Copyright: (c) 2021 by the authors. Licensee MDPI, Basel, Switzerland. This article is an open access article distributed under the terms and conditions of the Creative Commons Attribution (CC BY) license (https:// creativecommons.org/licenses/by/ $4.0 /)$.

\begin{abstract}
In this paper, nickel-containing residue, a typical solid waste produced in the battery production process, was used to study the cavitation characteristics of ultrasonic waves in a liquid-solid reaction. The ultrasonically-enhanced leaching technology for multicomponent and complex nickelcontaining residue was studied through systematic ultrasonic-conventional comparative experiments. An ultrasonic leaching kinetics model was established which provided reliable technological guidance and basic theory for the comprehensive utilization of nickel-containing residue. In the study, it was found that ultrasonically-enhanced leaching for $40 \mathrm{~min}$ obtained the same result as conventional leaching for $80 \mathrm{~min}$, and the $\mathrm{Ni}$ extraction degree reached more than $95 \%$. According to the kinetic fitting of the leaching process, it was found that the sulfuric acid leaching process belonged to the diffusion-controlled model of solid product layers under conventional and ultrasonic conditions, and the activation energy of the reaction was $E_{\mathrm{a} 1}=17.74 \mathrm{~kJ} / \mathrm{mol}$ and $E_{\mathrm{a} 2}=5.04 \mathrm{~kJ} / \mathrm{mol}$, respectively.
\end{abstract}

Keywords: leaching; ultrasound; nickel-containing residue

\section{Introduction}

In recent years, with the rapid development of the battery industry, the amount of wastewater containing heavy metals produced by battery enterprises is increasing [1]. At present, a chemical precipitation method is commonly used to treat the wastewater where the heavy metal ions are transferred to the waste residue, thus forming a multi-component hazardous waste containing $\mathrm{Ni}, \mathrm{Cd}, \mathrm{Fe}, \mathrm{Cu}, \mathrm{Ca}$, and other metals [2,3]. The nickel in the residue produced by battery enterprises typically exists in the form of a hydrate. The nickel content in the residue is generally about $10 \mathrm{wt} \%$, and its elemental content is much higher than that of the ore, so it has a high utilization value.

Nickel-containing residue is unfortunately easily accumulated, unstable, and dissolves easily in water. If it is not treated or contained, it will cause serious pollution issues in soil and groundwater and will result in further damage to human health and the environment $[4,5]$. Many researchers have worked on the comprehensive treatment of waste residue containing heavy metals and have rapidly developed methods in recent years, resulting in encouraging progress [6,7]. Among the developed methods, the recovery of heavy metals through sulfuric acid leaching or ammonia leaching are key points in these studies, as well as other ways to selectively recover valuable metals [8,9].

The acid-leaching method is an effective leaching method. Silva et al. [10] studied the leaching of sludge from a nickel plating plant using a sulfuric acid medium and an ammonia medium. The maximum nickel conversion was $98.0 \%$ under the following experimental conditions: $100 \mathrm{~g} / \mathrm{L}$ acid concentration, 5:1 liquid-solid ratio, particle size less than $1 \mathrm{~mm}$, digestion time $1 \mathrm{~h}$, stirring speed $700 \mathrm{rpm}$ (all at room temperature and atmospheric pressure). Nickel could be extracted without $\mathrm{Cr}$ using an ammonia medium, but the nickel conversion rate was only $50 \%$, which is much lower than that of sulfuric acid leaching. This was because the metals in the sludge mainly existed in the form of oxides 
or hydroxides. Therefore, by adding acid to the electroplating sludge, most of the metals dissolved by forming soluble ions or coordination ions. Su et al. [11] studied the effect of leaching valuable metals from the electroplating sludge under acidic conditions and found that the leaching rate of copper was as high as $80.6 \%$ when the concentration of phosphate participation in hydrochloric acid medium was $1.5 \mathrm{~mol} / \mathrm{L}$, the liquid-solid ratio was 10:1, and the temperature was $40^{\circ} \mathrm{C}$. By adding stearyltrimethyl ammonium chloride (STAC), Zhang et al. [12] improved the ion diffusion, and thus the leaching rate of $\mathrm{Ni}$ increased from $64.9 \%$ to $74.1 \%$ after $6 \mathrm{~h}$ of leaching in $8 \mathrm{wt} \%$ sulfuric acid, and with a liquid-solid ratio $(v / w)$ of 10 at $90{ }^{\circ} \mathrm{C}$.

The recovery of valuable metals from nickel-containing residue generally requires certain temperature conditions, harsh operating conditions, a large amount of acid, and leaves a large amount of acid waste. Therefore, it is necessary to develop a new process with milder conditions and high efficiency.

Since the first International Symposium on Sonochemistry was held in the U.K. in 1986, ultrasound has attracted much attention as an important means of enhancing the leaching process [13-15]. When the ultrasonic intensity is high enough, cavitation will occur. During cavitation, bubbles in the solution form, oscillate, grow, shrink, and finally collapse, all within a short time and a small space. This process produces a temperature of more than $5000 \mathrm{~K}$ and a pressure of about $5 \times 10^{7} \mathrm{~Pa}$, accompanied by a strong shock wave [16-18]. When the ultrasonic intensity is insufficient to produce cavitation, the mechanical effect strongly agitates the liquid, reduces the diffusion resistance, destroys the boundary layer, and therefore accelerates the mass and heat transfer [14].

In light of the difficult treatment of lead in an electrolytic manganese anode sludge, Xie et al. [19] proposed a method combining a conventional roasting pretreatment with an ultrasonically enhanced leaching of ammonium acetate. They found that both conventional and ultrasonic leaching processes were controlled by diffusion, and the activation energies of conventional and ultrasonic leaching processes were $29.40 \mathrm{~kJ} / \mathrm{mol}$ and $26.95 \mathrm{~kJ} / \mathrm{mol}$, respectively. Nivetha et al. [20] used a sulfuric acid solvent as the leaching agent to extract nickel ions from spent batteries and found that the leaching rate after ultrasonic-assisted leaching was $98.5 \%$, and the rate after conventional leaching was $90.8 \%$. Gui et al. [21] studied the influence of ultrasonic waves on the leaching of gold and found that under ultrasonic conditions, the gold leaching speed was eight times as fast as that under conventional conditions, and the leaching rate was increased by about $25 \%$. Additionally, the activation energy decreased from $22.65 \mathrm{~kJ} / \mathrm{mol}$ to $13.86 \mathrm{~kJ} / \mathrm{mol}$.

In this paper, the nickel-containing residue produced from battery manufacturing was used as raw material, and the ultrasonic method was used to supplement an acid leaching process. The effects on the reaction temperature, mass fraction of acid, and the ratio of liquid to solid on the Ni extraction degree were investigated to obtain more suitable process parameters. This study was completed to find a more efficient, environmentally friendly, and economic nickel leaching process.

\section{Materials and Methods}

\subsection{Raw Materials}

In this study, nickel-containing residue produced by the chemical precipitation of wastewater from a battery manufacturing enterprise in Henan, China, was used as the raw material. Figures 1 and 2 show the major components and microstructure of the sample after pretreatment as reported in our earlier study [22,23]. After pretreating the sample via roasting, the gaspeite and nickel hydroxide hydrate in the residue was found to be transformed into bunsenite without altering the major species of the other metal elements in the residue. A reduction of the weight of the residue by more than $20 \%$ was observed $(1 \mathrm{~g}$ of dried nickel-containing residue was roasted at $1000^{\circ} \mathrm{C}$ for $1 \mathrm{~h}$, the measured LOI (loss on ignition) value of nickel-containing residue was $43.57 \%$ ). As shown in Figure 1, calcite was found to be the major component, and Ni mainly existed in bunsenite, while small 
amounts of quartz and magnesium silicate were also present. It can be seen in Figure 2 that the surface of the sample particles was rough and the microscopic shape was irregular

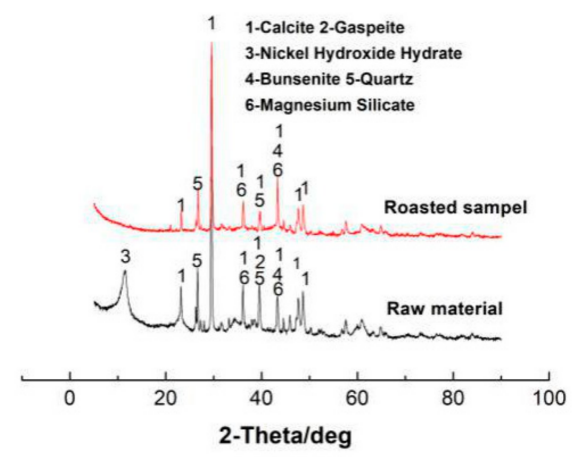

Figure 1. X-ray diffraction pattern of the nickel-containing residue.

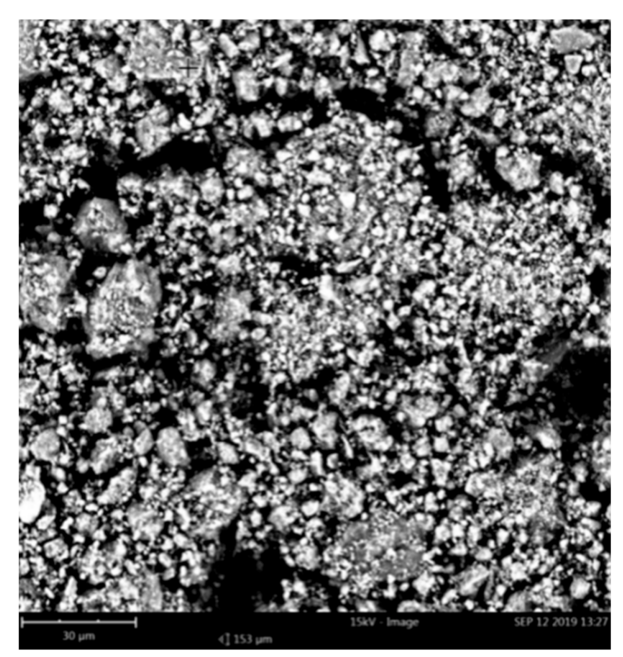

Figure 2. SEM of the residue after pretreatment.

Table 1 shows the chemical composition of the nickel-containing residue determined by mineralogical analysis and $\mathrm{X}$-ray fluorescence. The residue mainly contained $35.88 \%$ $\mathrm{CaO}, 16.21 \% \mathrm{MgO}, 13.81 \% \mathrm{NiO}, 8.02 \% \mathrm{Fe}_{2} \mathrm{O}_{3}, 5.07 \% \mathrm{SiO}_{2}$, and $1.05 \% \mathrm{CdO}$.

Table 1. The main components of the nickel-containing residue.

\begin{tabular}{ccccccccc}
\hline Composition & $\mathrm{CaO}$ & $\mathrm{MgO}$ & $\mathrm{NiO}$ & $\mathrm{Fe}_{2} \mathrm{O}_{3}$ & $\mathrm{SiO}_{2}$ & $\mathrm{CdO}$ & $\mathrm{Al}_{2} \mathrm{O}_{3}$ & $\mathrm{ZnO}$ \\
\hline Content $(\mathrm{wt} \%)$ & 35.88 & 16.21 & 13.81 & 8.02 & 5.07 & 1.05 & 1.01 & 0.63 \\
\hline
\end{tabular}

\subsection{Experimental Methods and Devices}

Conventional leaching: $10 \mathrm{~g}$ of the residue having different particle sizes $(-250,-180$, $-150,-120,-109,-96$, and $-80 \mu \mathrm{m})$ was weighed into a $150 \mathrm{~mL}$ circular beaker. Sulfuric acid having different mass fractions $(5 \%, 10 \%, 15 \%$, and $20 \%$ ) was added into the beaker in different specific solid-liquid ratios (1:5, 1:6, 1:7, 1:8, and 1:9) and the beaker was placed into a thermostatic water bath equipped with a magnetic stirrer. The residue was treated for different time intervals from 0-80 min under different temperatures $(25,35,45$, and $55^{\circ} \mathrm{C}$ ) using a stirring speed of $150 \mathrm{rpm}$.

Ultrasonic leaching: The details of the treatment procedure were similar to the conventional leaching described above other than the fact that the samples were treated in an ultrasonic bath having different ultrasonic power levels $(300,400,500,600,700$, and $800 \mathrm{~W})$ for $0-45 \mathrm{~min}$. 
Characterization: In order to determine the extent of nickel leaching, the leached solution was analyzed for its nickel content before and after the leaching via inductively coupled plasma optical emission spectrometry (ICP, Agilent5100, Agilent Technologies, Palo Alto, CA, USA). Changes of the microstructure and phase after leaching were analyzed by SEM-EDS (SPM-S3400N, Hitachi, Tokyo, Japan) and X-ray powder diffraction (XRD) (XRD-7000S/L, Shimadzu, Kyoto, Japan), respectively. Particle size of the leached residue was analyzed by laser particle size distribution tester (Mastersizer 3000, Malvern, England). The specific surface area of the leached slag was determined by a specific surface area analyzer (BET) (ASAP 2460, Micromeritics, Shanghai, China).

Experimental device: The ultrasonic leaching system used in the experiment was a self-developed ultrasonic leaching system based on reported literature [15]. A schematic of the system is shown in Figure 3. The device consists of a ultrasonic generator (QHY-1200, Wuxi, China) which was composed of a quartz probe with a diameter of $8 \mathrm{~mm}$ and a thermostatic water bath equipped with a magnetic stirrer (DK-98-IIA, Tianjing, China). The leaching temperature was controlled within $\pm 2{ }^{\circ} \mathrm{C}$.

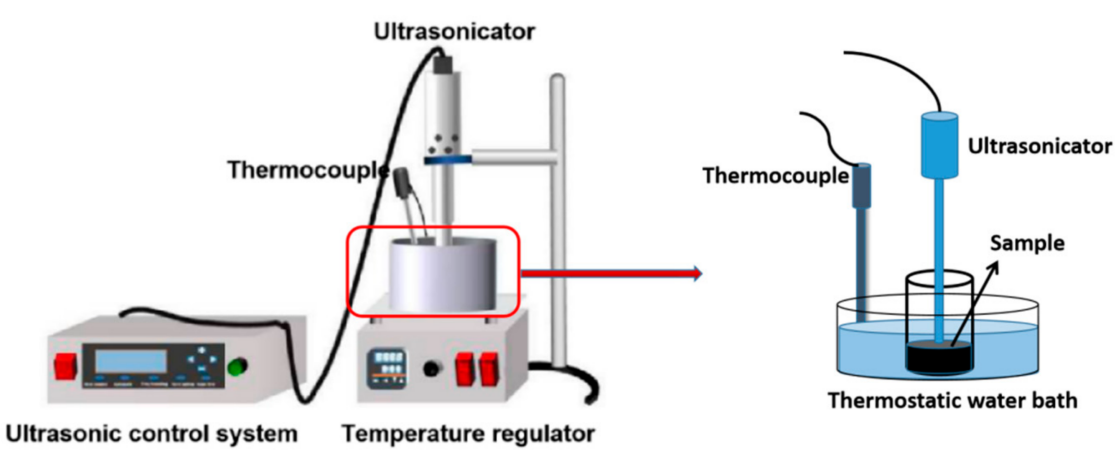

Figure 3. The ultrasonically enhanced leaching system.

\subsection{Data Analysis and Mathematical Modeling}

As shown in Figure 1, calcite was found to be the major component, and Ni mainly existed in bunsenite. The reaction between bunsenite, calcite, and sulfuric acid:

$$
\begin{aligned}
& \mathrm{NiO}(\mathrm{s})+\mathrm{H}_{2} \mathrm{SO}_{4}(\mathrm{l})=\mathrm{NiSO}_{4}(\mathrm{aq})+\mathrm{H}_{2} \mathrm{O}(\mathrm{l}) \\
& \mathrm{CaCO}_{3}(\mathrm{~s})+\mathrm{H}_{2} \mathrm{SO}_{4}(\mathrm{l})=\mathrm{CaSO}_{4}(\mathrm{~s})+\mathrm{H}_{2} \mathrm{O}(\mathrm{l})
\end{aligned}
$$

Using the results obtained in the present work and assuming reaction (1), the kinetics of the leaching process can be evaluated. The shrinking core model can be used to describe the kinetics of heterogeneous reactions in non-porous materials. When the control step is internal diffusion, the process can be expressed as:

$$
1-2 / 3 x-(1-x)^{2 / 3}=k_{d} t
$$

where $x$ is the Ni extraction degree $(\%), k_{\mathrm{d}}$ is the diffusion velocity constant, and $t$ is the reaction time $(\mathrm{min})$.

When the control step is a surface chemical reaction, the process can be expressed as:

$$
1-(1-x)^{1 / 3}=k_{c} t
$$

where $x$ is the Ni extraction degree (\%), $k_{c}$ is the surface chemical reaction rate constant, and $t$ is the reaction time ( $\mathrm{min}$ ).

Dickinson and Heal [24] proposed a new modification of the shrinking core model which may be preferable for describing the kinetics of leaching reactions controlled by the interfacial transfer and internal diffusion:

$$
1 / 3 \ln (1-x)+(1-x)^{-1 / 3}-1=k_{b} t
$$


where $x$ is the Ni extraction degree (\%), $k_{b}$ is the apparent rate constant, and $t$ is the reaction time ( $\mathrm{min})$.

The activation energy of the reaction was calculated according to the Arrhenius equation.

$$
k=A \exp \left(\frac{-E_{\mathrm{a}}}{R T}\right)
$$

$E_{\mathrm{a}}$ is the activation energy $(\mathrm{kJ} / \mathrm{mol}), A$ is the pre-exponential coefficient, $R$ is the gas constant $8.314 \times 10^{-3} \mathrm{~kJ} /(\mathrm{mol} \cdot \mathrm{K})$, and $T$ is the reaction temperature $(\mathrm{K})$.

The calculation of the Ni extraction degree can be expressed as:

$$
\mathrm{Ni}(\%)=\frac{m_{\mathrm{Ni}, 0}-m_{\mathrm{Ni}}}{m_{\mathrm{Ni}, 0}}
$$

where, $m_{\mathrm{Ni}, 0}$ is the nickel content in the residue, and $m_{\mathrm{Ni}}$ is the nickel content in the leached residue.

\section{Results}

\subsection{Effect of Leaching Temperature}

As seen in Figure 4, there was a continuous increase in the Ni extraction degree in the studied temperature range. As the temperature increased, the movement of solute or solvent molecules in the leaching system was accelerated, resulting in an accelerated leaching speed and an increase in the leaching rate. In the presence of ultrasonic conditions, the leaching rate of $25{ }^{\circ} \mathrm{C}$ temperature for $40 \mathrm{~min}$ showed the same value for $55^{\circ} \mathrm{C}$ temperature under conventional conditions over a period of $80 \mathrm{~min}$, with the Ni extraction degree reaching about $95 \%$. By comparing Figure $4 a, b$, it was seen that the influence of temperature on the $\mathrm{Ni}$ extraction degree under ultrasonic conditions was significantly smaller than that under conventional conditions. In general, an increase in reaction temperature resulted in ion diffusion through the solid masses. However, under ultrasonic conditions, there was solid surface exfoliation and production of ultrasonic cavitation micro jets which reduced the diffusion layer thickness, increased the particle surface area, and therefore greatly improved the internal diffusion of reactive ions. Hence, the Ni extraction degree was less sensitive to increasing temperatures under ultrasonic conditions. In order to achieve high leaching rate while saving energy, the ultrasonic leaching process of $40 \mathrm{~min}$ at $25{ }^{\circ} \mathrm{C}$ temperature was selected for further studies.

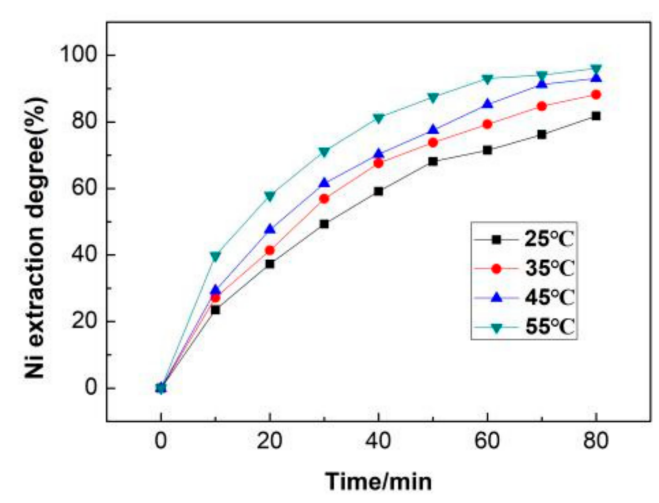

(a) Conventional

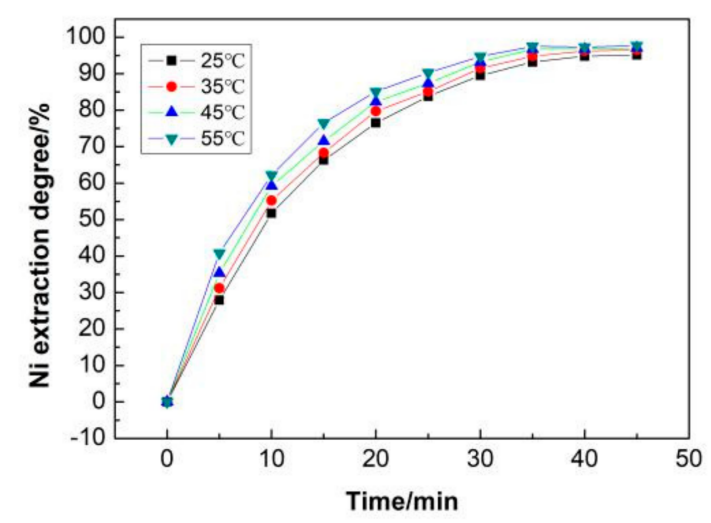

(b) Ultrasonic

Figure 4. Influence of the temperature on the Ni extraction degree. (a) Conventional: mass fraction of sulfuric acid $=15 \%$, solid-liquid ratio $=1: 7$, particle size $=-150 \mu \mathrm{m}$, stirring speed $=150 \mathrm{rpm} ;(\mathbf{b})$ ultrasonic: mass fraction of sulfuric acid $=15 \%$, solid-liquid ratio $=1: 7$, particle size $=-150 \mu \mathrm{m}$, ultrasonic power $=600 \mathrm{~W}$. 


\subsection{Effect of Sulfuric Acid Concentration}

It can be seen in Figure 5 that the Ni extraction degree increased with the increase in the mass fraction of sulfuric acid in the studied range. This is because the solution provided additional hydrogen ions with the increase in the mass fraction of sulfuric acid, therefore, all the alkaline nickel compounds were converted to free nickel ions which improved the $\mathrm{Ni}$ extraction degree. By comparing Figure $5 \mathrm{a}, \mathrm{b}$, it was found that the concentration of the leaching agent had a significant effect on the conventional leaching process. In the presence of ultrasonic conditions, for $15 \%$ sulfuric acid as the leachant, the Ni extraction degree was about $95 \%$ after leaching for $40 \mathrm{~min}$. Under identical conditions, ultrasound wave is able to achieve better results compared with conventional leaching in low concentration of sulfuric acid. When the concentration of this leaching agent was low, the viscosity was small, and the cavitation bubbles were easily generated. Moreover, the energy loss in the propagation process was small, which was conducive to the asymmetric bursting of the intermingling bubbles near the holes of particles, which therefore increased the diffusion and mass transfer velocity in the particles, shortened the reaction time, and improved the leaching rate. As a result, for further studies, $15 \%$ sulfuric acid was selected as the leaching agent under ultrasonic conditions.

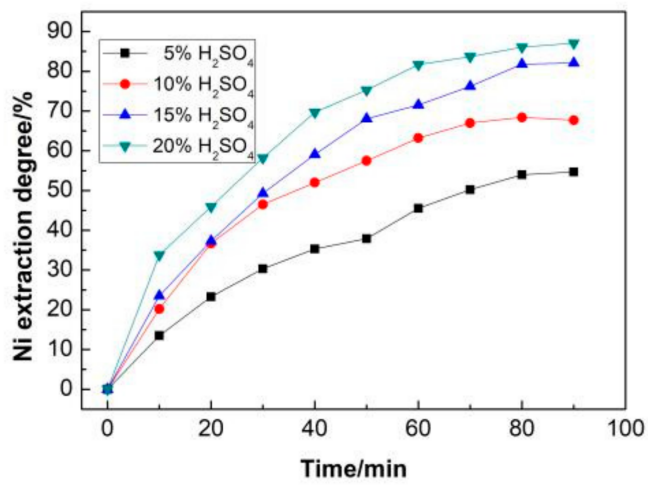

(a) Conventional

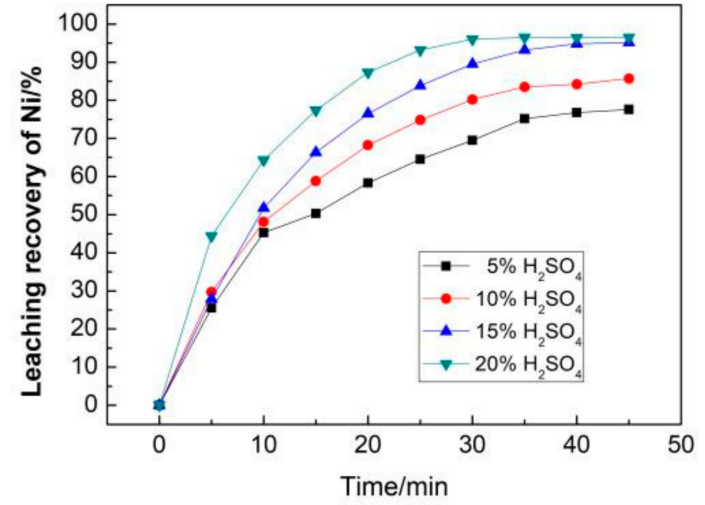

(b) Ultrasonic

Figure 5. The influence of sulfuric acid concentration on the Ni extraction degree. (a) Conventional: temperature $=25^{\circ} \mathrm{C}$, solid-liquid ratio $=1: 7$, particle size $=-150 \mu \mathrm{m}$, stirring speed $=150 \mathrm{rpm}$; $(\mathbf{b})$ ultrasonic: temperature $=25^{\circ} \mathrm{C}$, solid-liquid ratio $=1: 7$, ultrasonic power $=600 \mathrm{~W}$, particle size $=-150 \mu \mathrm{m}$.

\subsection{Effect of Particle Size}

It was seen from Figure 6 that the Ni extraction degree increased with the reduction of residue particle size, and the Ni extraction degree reached a higher level when the particle size was $-150 \mu \mathrm{m}$ under the ultrasonic conditions. In comparison, the influence of particle size on the Ni extraction degree under ultrasonic conditions was less than that under conventional conditions. The leaching rate was also proportional to the surface area of contact between liquid and solid. With the decrease in particle size, the contact area between the liquid and solid phases increased, and the internal diffusion resistance decreased, which was beneficial for improving the leaching effect of nickel. Under the ultrasonic field, cavitation bubbles had a certain peeling effect on the surface of solid particles. This effectively separated the insoluble layer on the surface of particles, resulting in constant production of new reaction interfaces, which caused a reduction in particle size during the leaching process, and reduced the impact of particle size on the leaching rate. Therefore, $150 \mu \mathrm{m}$ was selected as the residue particle size for further studies. 


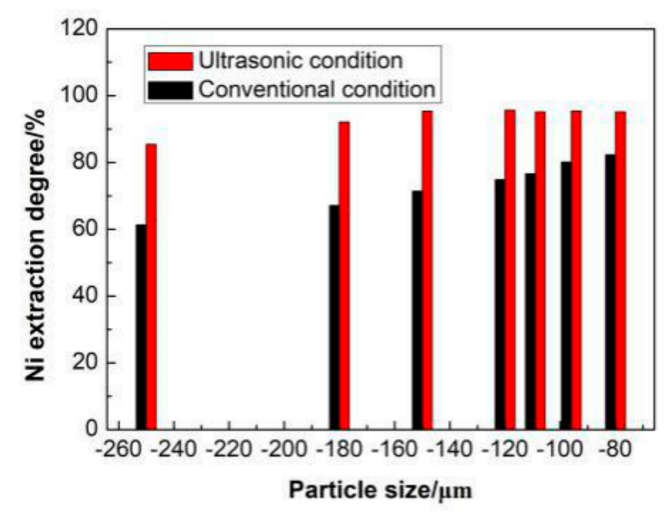

Figure 6. Effect of particle size on Ni extraction degree. Conventional: leaching temperature $=25^{\circ} \mathrm{C}$, mass fraction of sulfuric acid $=15 \%$, solid-liquid ratio $=1: 7$, stirring speed $=150 \mathrm{rpm}$, leaching time $=40 \mathrm{~min}$. Ultrasonic: leaching temperature $=25{ }^{\circ} \mathrm{C}$, mass fraction of sulfuric acid $=15 \%$, solid-liquid ratio $=1: 7$, ultrasonic power $=600 \mathrm{~W}$, leaching time $=40 \mathrm{~min}$.

\subsection{Effect of the Solid-Liquid Ratio}

It is evident from Figure 7 that with increasing solid-liquid ratio, the Ni extraction degree increased significantly till the solid-liquid ratio reached 1:7. When the solid-liquid ratio was 1:7, the Ni extraction degree reached a maximum of $95.04 \%$. This was because the increase in the solid-liquid ratio reduced the slurry's viscosity and improved the reaction ion diffusion conditions. Under ultrasonic conditions, the viscosity of the solution decreased when the solid-liquid ratio increased and the ultrasonic cavitation efficiency increased, leading to an increase in the leaching efficiency. The solid-liquid ratio was therefore selected as 1:7 for this experiment.

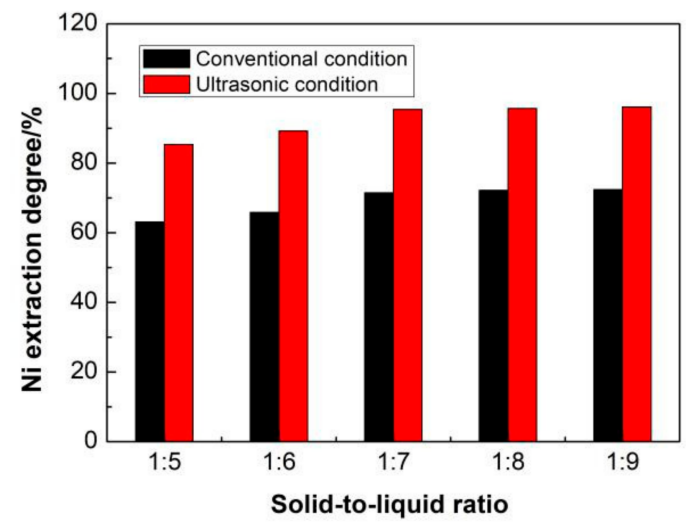

Figure 7. Effect of particle size on Ni extraction degree. Conventional: leaching temperature $=25^{\circ} \mathrm{C}$, mass fraction of sulfuric acid $=15 \%$, particle size $=-150 \mu \mathrm{m}$, stirring speed $=150 \mathrm{rpm}$, leaching time $=40 \mathrm{~min}$. Ultrasonic: leaching temperature $=25^{\circ} \mathrm{C}$, mass fraction of sulfuric acid $=15 \%$, particle size $=-150 \mu \mathrm{m}$, ultrasonic power $=600 \mathrm{~W}$, leaching time $=40 \mathrm{~min}$.

\subsection{Influence of Ultrasonic Power}

As seen from Figure 8, increasing ultrasonic power from $300 \mathrm{~W}$ to $600 \mathrm{~W}$ led to an increase in the Ni extraction degree. The pulse and cavitation generated by ultrasonic waves can greatly increase the turbulence intensity and the contact area, thus enhancing the mass transfer. When the ultrasonic power was $600 \mathrm{~W}$, the Ni extraction degree can increase to above $95 \%$, and with further increase in ultrasonic power there was very little change of the leaching rate. Higher ultrasonic power led to an acceleration of the leaching reaction of other metal elements, thus affecting the leaching of nickel. On the other hand, because of the high ultrasonic power, the cavitation bubble generated by it was too large for the cavitation effect to come into full play, so the Ni extraction degree did not increase 
when the ultrasonic power was higher than $600 \mathrm{~W}$. Therefore, the ultrasonic power was selected as $600 \mathrm{~W}$ for further experiments.

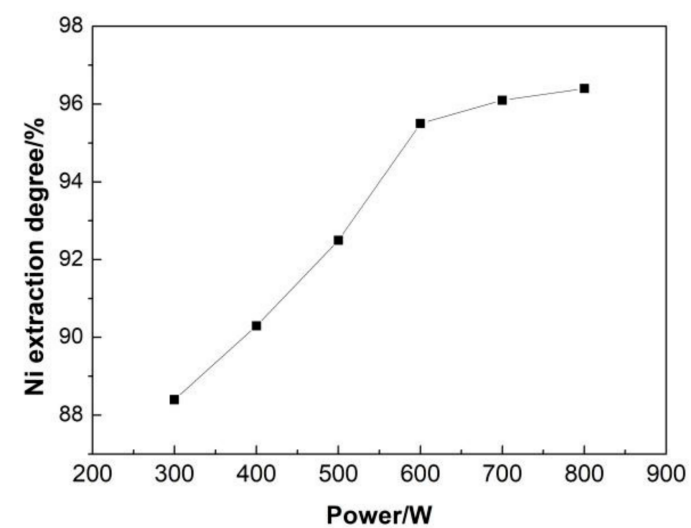

Figure 8. Influence of ultrasonic power on the Ni extraction degree. Leaching temperature $=25^{\circ} \mathrm{C}$, mass fraction of sulfuric acid $=15 \%$, particle size $=-150 \mu \mathrm{m}$, solid-liquid ratio $=1: 7$, leaching time $=40 \mathrm{~min}$.

\subsection{Leaching Kinetics}

As seen from Figure 4, with the increase in time, the Ni extraction degree also increased, but the leaching rate was not linear with time, indicating that boundary layer diffusion was not the main control step in the acid leaching process. The experimental data were substituted into Equations (1)-(3), respectively, and the fitting results are shown in Figure 9.

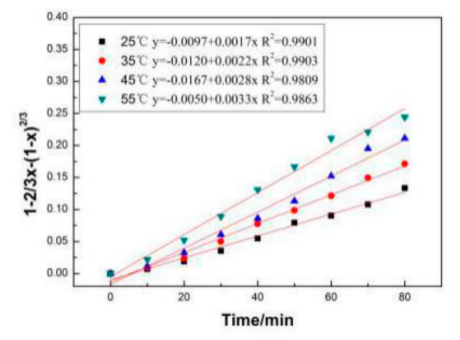

(a) Conventional

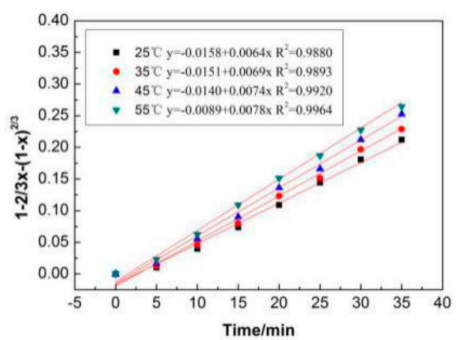

(d) Ultrasonic

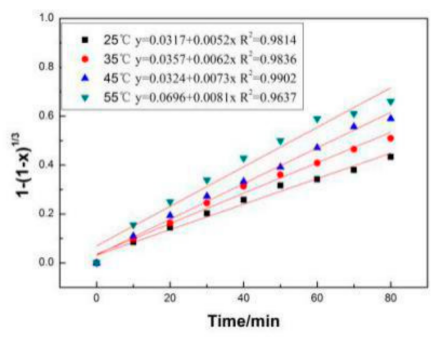

(b) Conventional

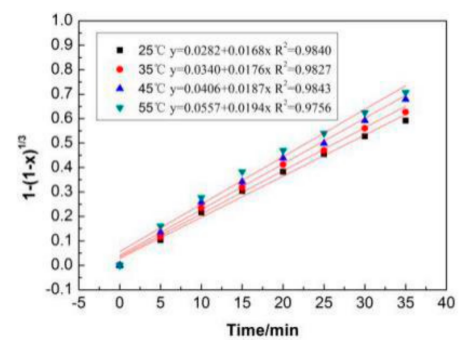

(e) Ultrasonic

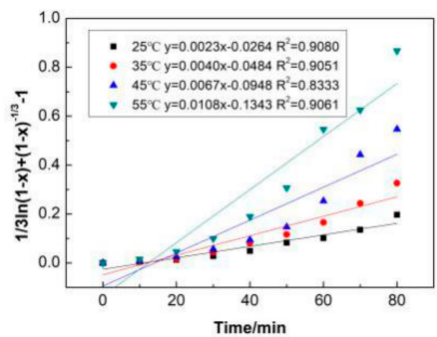

(c) Conventional

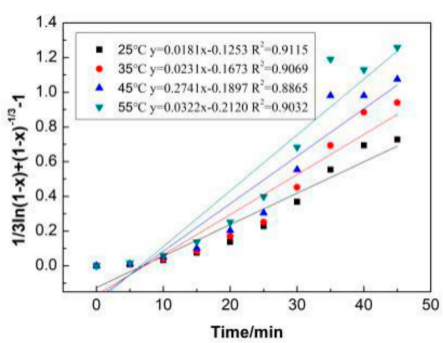

(f) Ultrasonic

Figure 9. Fitting of control steps at different temperatures.

The values of $\mathrm{R}^{2}$ in Figure 9 show that the internal diffusion control model better described the acid leaching process than that of other models under both conventional and ultrasonic conditions.

According to the Arrhenius Equation (4), taking $\mathrm{Lnk}_{\mathrm{d}}$ as the $Y$-axis and $\mathrm{T}^{-1}$ as the $X$-axis, Figure 10 can be obtained. 


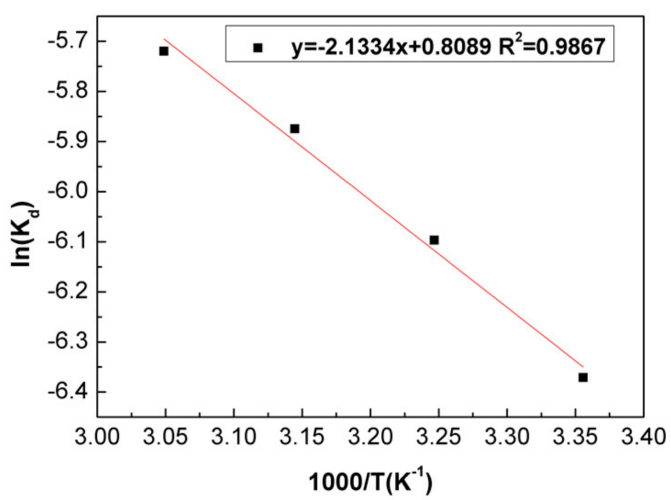

(a) Conventional

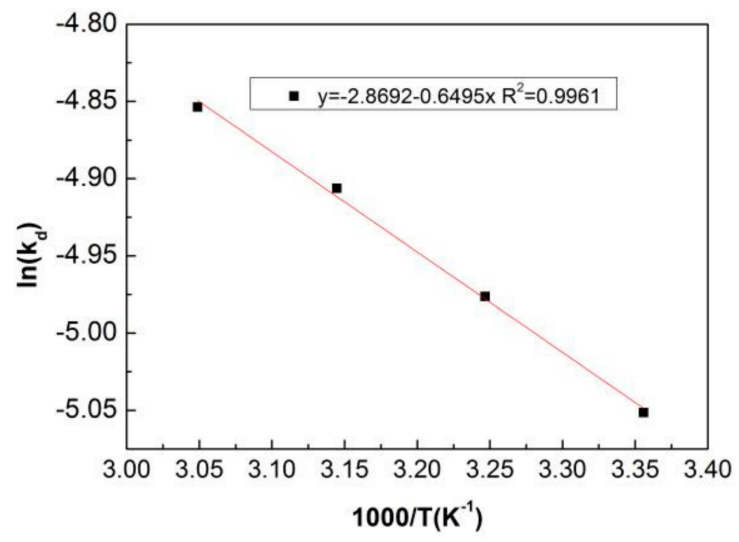

(b) Ultrasonic

Figure 10. The relation between $\mathrm{k}_{\mathrm{d}}$ and $\mathrm{T}^{-1}$.

According to Figure 10, the activation energies of the reaction under conventional and ultrasonic conditions were calculated as $E_{\mathrm{a} 1}=17.74 \mathrm{~kJ} / \mathrm{mol}$ and $E_{\mathrm{a} 2}=5.04 \mathrm{~kJ} / \mathrm{mol}$, respectively. Under conventional and ultrasonic conditions, the diffusion coefficients for sulfuric acid leaching are shown in Equations (8) and (9), respectively.

$$
\begin{aligned}
& K=2.2454 \times e^{-\frac{17.74}{R T}} \\
& K=0.05674 \times e^{-\frac{5.04}{R T}}
\end{aligned}
$$

According to Figure 5, the experimental data of the nickel leaching process at different sulfuric acid concentrations were substituted into the internal diffusion control model, and the fitting results are shown in Figure 11.

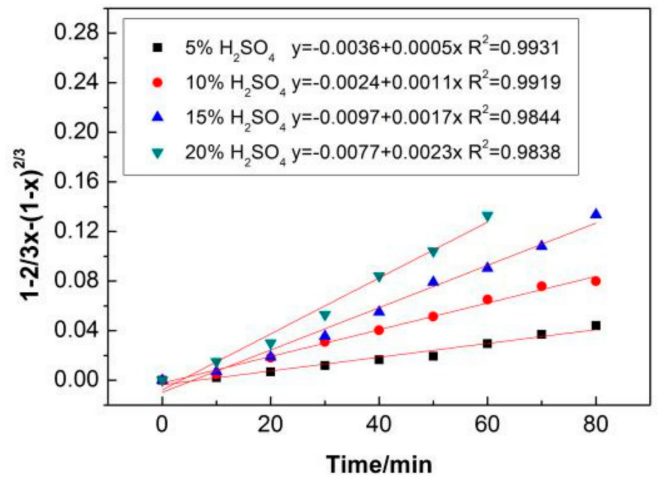

(a) Conventional

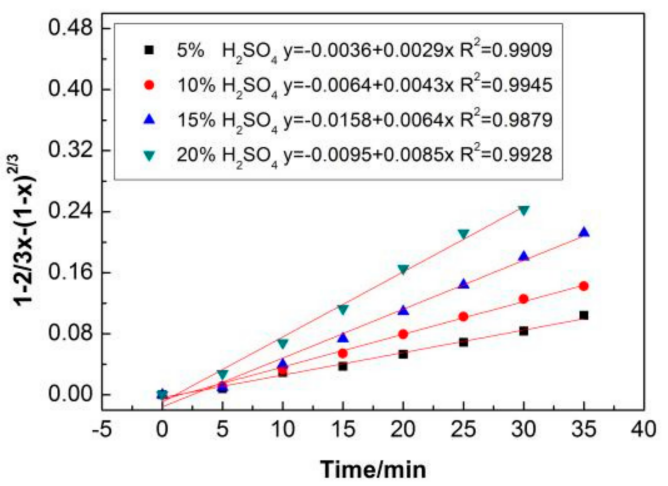

(b) Ultrasonic

Figure 11. Fitting internal diffusion control model at different sulfuric acid concentrations.

Taking $\ln k_{d}$ as the $Y$-axis and $\ln _{0}$ as the $X$-axis, Figure 12 was obtained.

As seen in Figure 12, the slope of the line is the kinetic series $n_{1}=0.9686$ and $n_{2}=0.7384$ under conventional and ultrasonic conditions, respectively. Therefore, the kinetic equation of the sulfuric acid leaching process can be expressed as Equations (10) and (11).

$$
\begin{aligned}
& 1-2 / 3 x-(1-x)^{2 / 3}=\frac{2 M D^{\prime} c_{0}{ }^{0.9686}}{\sigma \rho r_{0}^{2}} t \\
& 1-2 / 3 x-(1-x)^{2 / 3}=\frac{2 M D^{\prime} c_{0}{ }^{0.7384}}{\sigma \rho r_{0}^{2}} t
\end{aligned}
$$




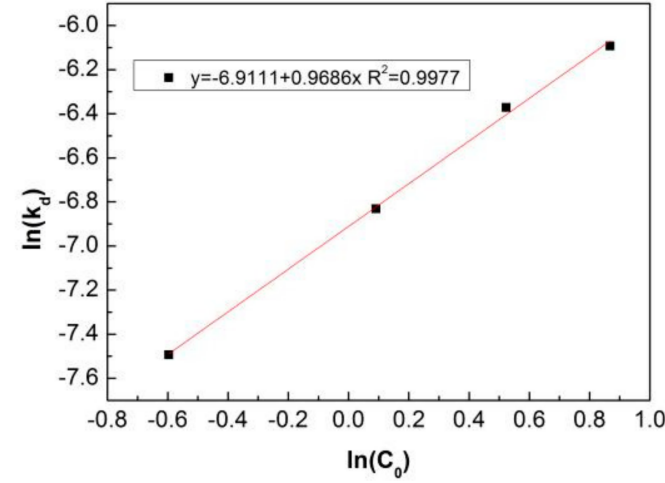

(a) Conventional

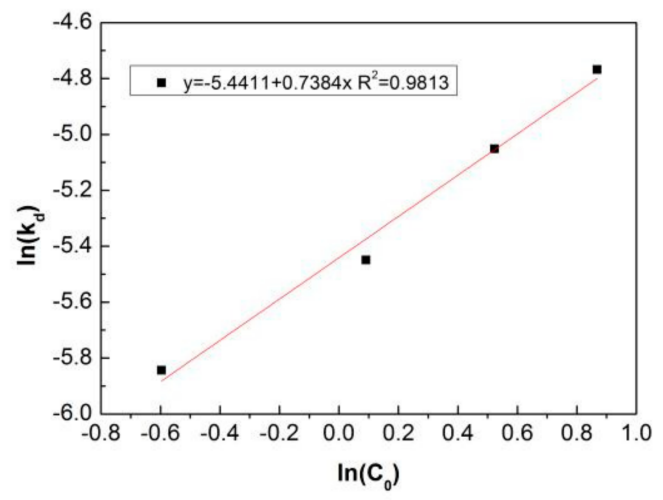

(b) Ultrasonic

Figure 12. Relationship between $\ln k_{d}$ and $\ln C_{0}$.

\subsection{Analysis of the Leached Residue}

As seen in Figure 13 and Table 2, after sulfuric acid leaching, the main phase in the material changed from calcite to gypsum. In addition, the Ni present in the material was almost entirely leached by sulfuric acid. Therefore, this proved that it was feasible to leach nickel from battery manufacturing residue by sulfuric acid. In addition, it can be found from Table 2 that under ultrasonic conditions, the valuable metals in the nickel-containing residue were separated into the liquid phase with a higher efficiency than that of the conventional conditions.

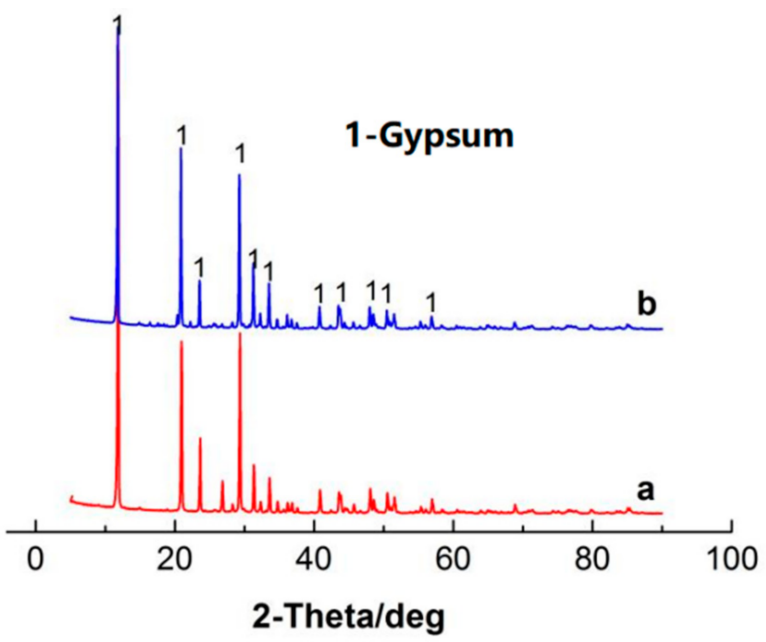

Figure 13. XRD pattern of the residue after sulfuric acid leaching. (a) Conventional: mass fraction of sulfuric acid $=15 \%$, particle size $=-150 \mu \mathrm{m}$, solid-liquid ratio $=1: 7$, temperature $=25^{\circ} \mathrm{C}$, stirring speed $=150 \mathrm{rpm}$, leaching time $=80 \mathrm{~min}$; (b) ultrasonic: power $=600 \mathrm{~W}$, mass fraction of sulfuric acid $=15 \%$, particle size $=-150 \mu \mathrm{m}$, solid-liquid ratio $=1: 7$, temperature $=25^{\circ} \mathrm{C}$, leaching time $=40 \mathrm{~min}$.

Table 2. The main components of the leached residue after conventional and ultrasonic leaching.

\begin{tabular}{ccccccccccc}
\hline \multicolumn{2}{c}{ Composition } & $\mathrm{SO}_{3}$ & $\mathrm{CaO}$ & $\mathrm{SiO}_{2}$ & $\mathrm{Fe}_{2} \mathbf{O}_{3}$ & $\mathbf{N i O}$ & $\mathbf{M g O}$ & $\mathrm{Al}_{2} \mathrm{O}_{3}$ & $\mathrm{ZnO}$ & $\mathrm{CdO}$ \\
\hline Conventional & Content $(\mathrm{wt} \%)$ & 53.925 & 25.312 & 2.41 & 1.68 & 1.62 & 0.897 & 0.308 & 0.055 & 0.207 \\
Ultrasonic & Content $(\mathrm{wt} \%)$ & 53.441 & 27.826 & 1.96 & 0.855 & 0.336 & 0.797 & 0.293 & 0.048 & 0.104 \\
\hline
\end{tabular}

As can be seen from Figure 14a, after conventional sulfuric acid leaching of nickel, there was a microstructural change of the residue with its surface becoming smooth from rough and irregular and was covered with a small amount of floc. Moreover, these regular 
shaped particles with a smooth surface tend to agglomerate. Figure $14 \mathrm{~b}$ shows the scanning electron microscope images of the residue after sulfuric acid leaching of nickel under an ultrasonic field. Compared with Figure 14a, no agglomeration of the residue particles was observed after sulfuric acid leaching under an ultrasonic field. The stripping effect of ultrasonic cavitation led to obvious fracture marks on the boundary of the leached residue, which is conducive to elimination of the surface film of the solid reactants and enhance the mass transfer between the solution and the solid pores or micropores, thus reducing the internal diffusion resistance. The kinetic fitting results are consistent with this result. Ultrasonic treatment strengthened the leaching process and reduced the reaction activation energy.

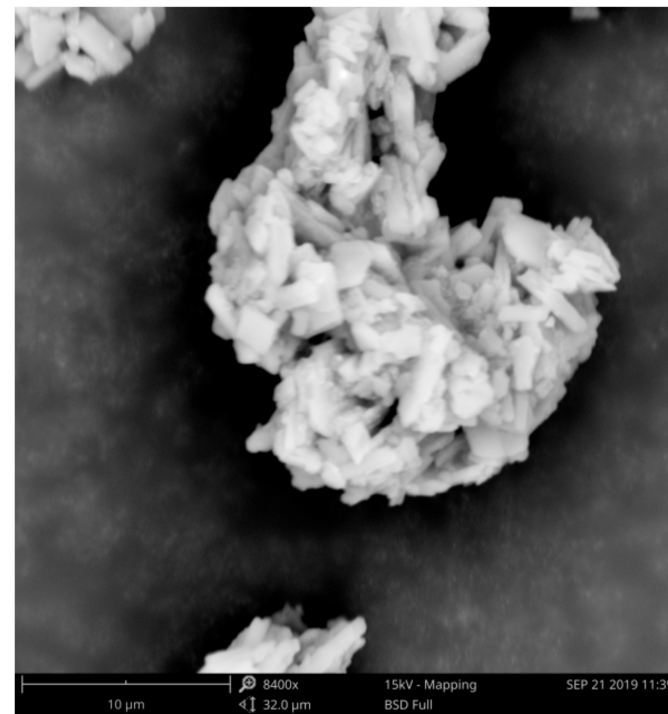

(a) Conventional

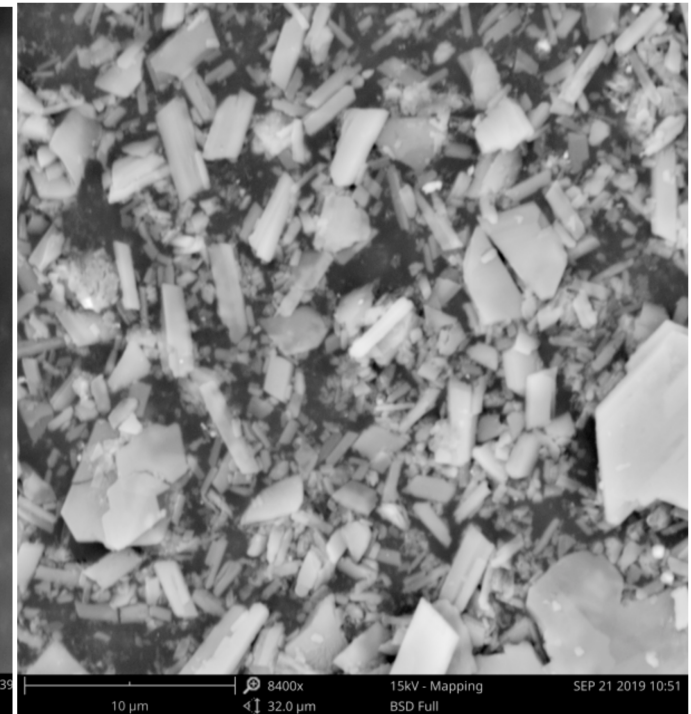

(b) Ultrasonic

Figure 14. SEM of residue after leaching. (a) Conventional: mass fraction of sulfuric acid $=15 \%$, particle size $=-150 \mu \mathrm{m}$, solid-liquid ratio $=1: 7$, temperature $=25^{\circ} \mathrm{C}$, stirring speed $=150 \mathrm{rpm}$, leaching time $=80 \mathrm{~min}$; (b) ultrasonic: power $=600 \mathrm{~W}$, mass fraction of sulfuric acid $=15 \%$, particle size $=-150 \mu \mathrm{m}$, solid-liquid ratio $=1: 7$, temperature $=25^{\circ} \mathrm{C}$, leaching time $=40 \mathrm{~min}$.

EDS analysis of the granular matter with a regular shape and smooth surface showed that it was mainly $\mathrm{CaSO}_{4}$ with a small amount of $\mathrm{CaCO}_{3}$, while the floc material of leached residue from conventional leaching also contained a certain amount of nickel as can be seen in Figure 15a. This was consistent with the data from other conventional leaching experiments. As shown in Figure 15b, the surface of the leaching residue under ultrasonic conditions was smooth and clean, which was composed of particles with regular shape and high dispersion.

Figure 16 shows the particle size distribution of leached residue after conventional and ultrasonic leaching. It can be found from Figure 16 that the leached residue from ultrasonic leaching have a smaller particle size than that of conventional leaching. The main reason is that the ultrasonic wave prevents the agglomeration of the leached residue in the leaching process. In addition, the high temperature and high pressure micro-jet generated by ultrasonic cavitation can peel off the particle surface, as Zhang [16] and Kumar [20] report. In addition, the specific surface of the leached residue under ultrasonic conditions is $58.9057 \mathrm{~m}^{2} / \mathrm{g}$, which is $16.25 \%$ higher than that under conventional conditions, shown in Table 3. Therefore, ultrasonic can promote the subsequent leaching process. 

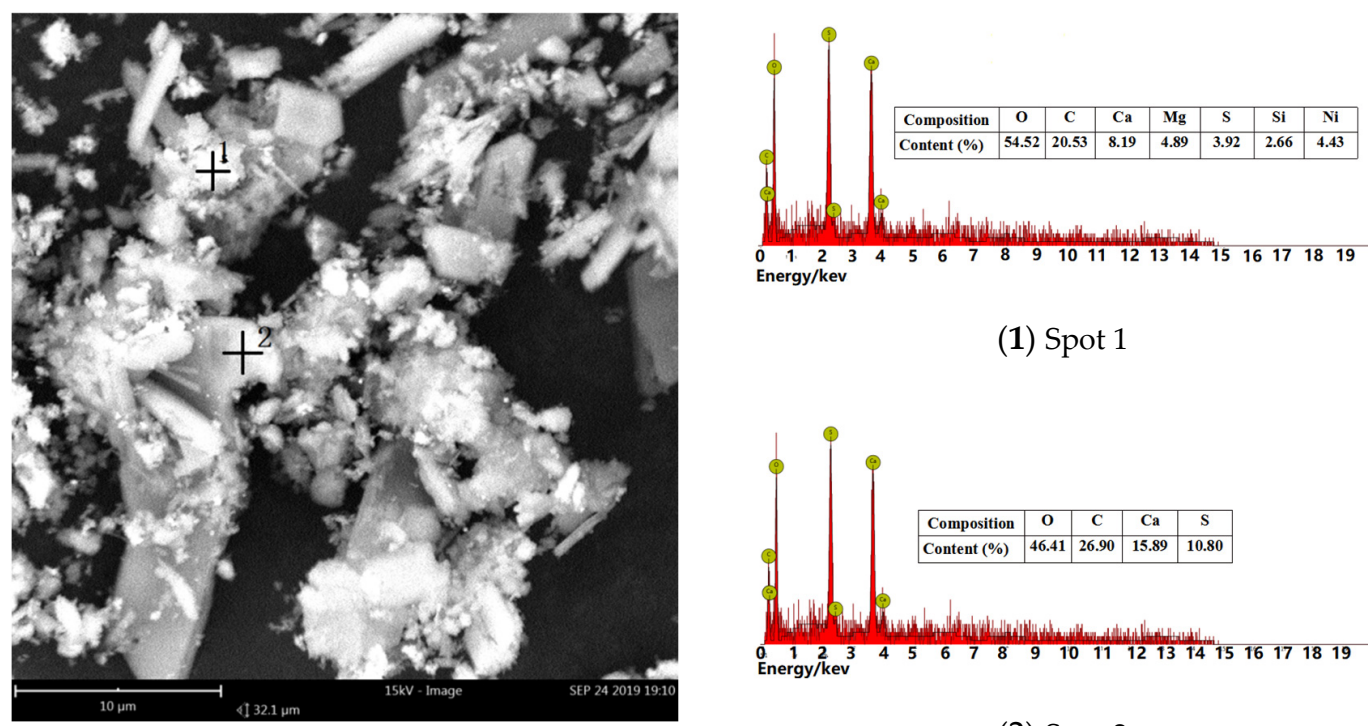

(1) Spot 1

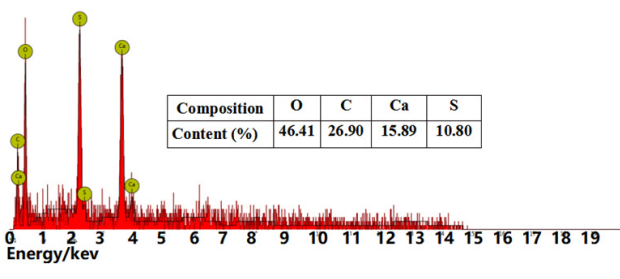

(2) Spot 2

(a) Conventional
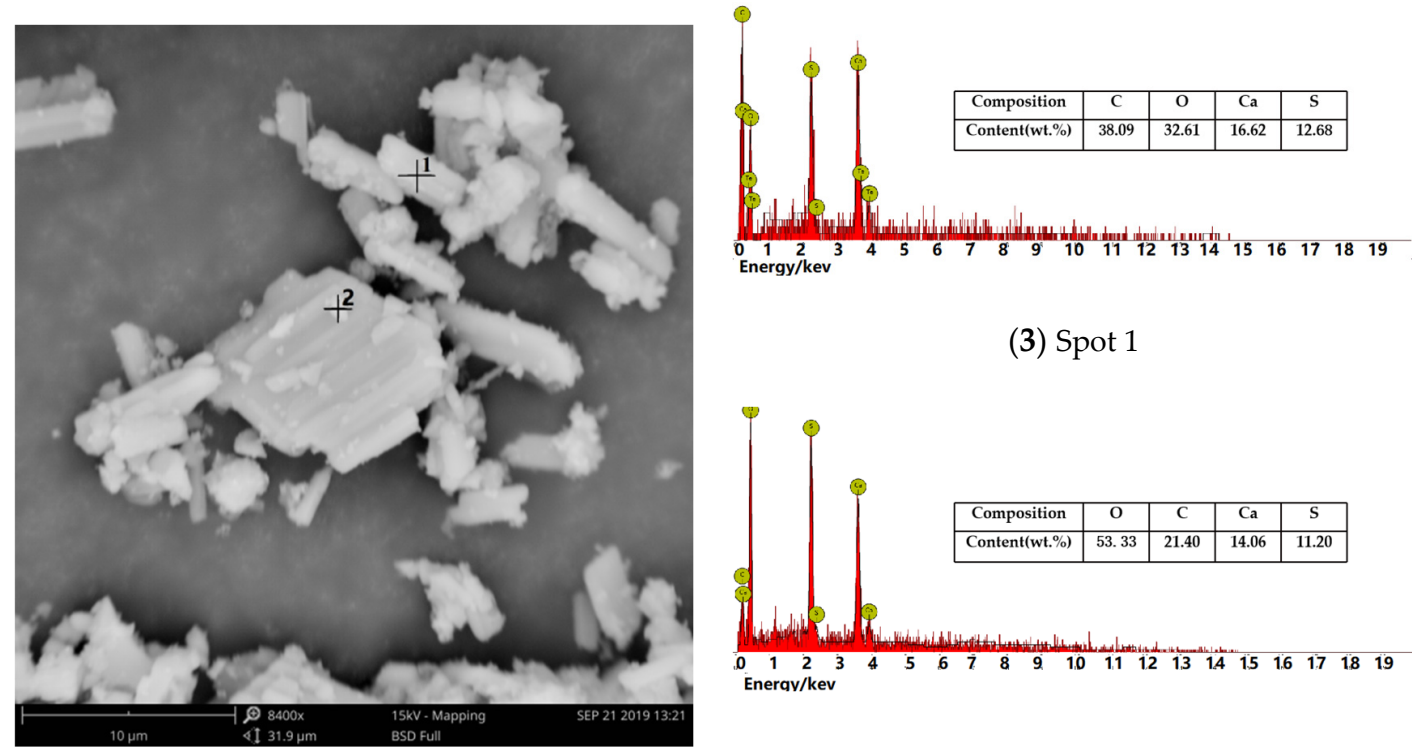

(3) Spot 1

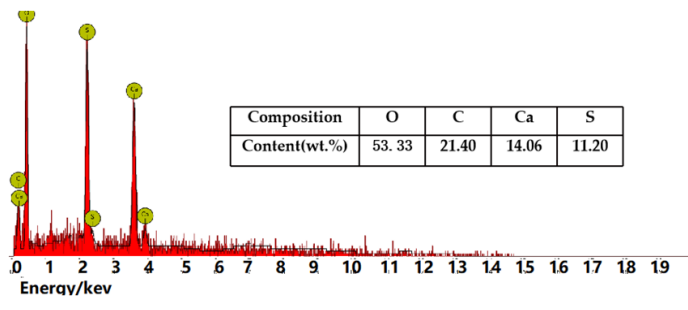

(4) Spot 2

(b) Ultrasonic

Figure 15. EDS analysis of the residue after leaching.

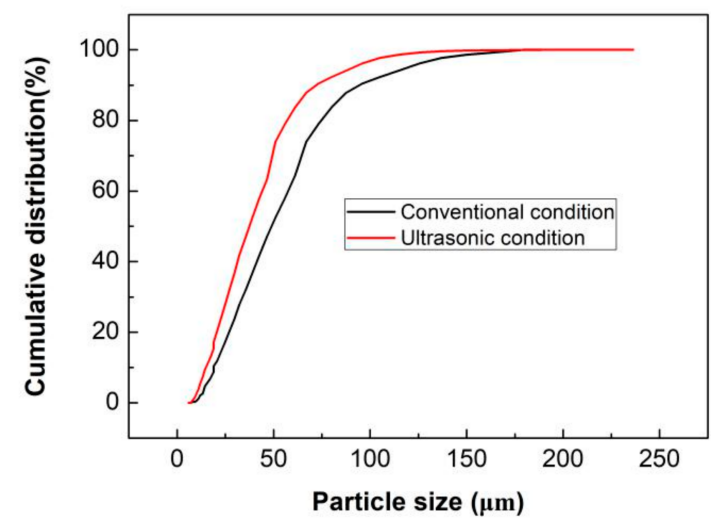

Figure 16. The particle size distribution of leached residue after conventional and ultrasonic leaching. 
Table 3. Specific surface area of leached slag under conventional and ultrasonic conditions.

\begin{tabular}{cc}
\hline Sample & BET Surface Area \\
\hline Ultrasonic & $58.9057 \mathrm{~m}^{2} / \mathrm{g}$ \\
Conventional & $50.6720 \mathrm{~m}^{2} / \mathrm{g}$ \\
\hline
\end{tabular}

It can be found from Table 4 that the chemical composition of the leaching solution mainly contains nickel, magnesium, and iron, and a small amount of cadmium and aluminum exists. At the same time, it can be found that the content of metal elements in the leaching solution under ultrasonic conditions is higher than conventional conditions. Chemical precipitation and solvent extraction are commonly used to separate, purify, and recover metals from the leach solution [25]. Impurity elements such as magnesium, iron, aluminum, and cadmium can be removed by precipitation and/or solvent extraction. However, in these processes, especially in the precipitation process, there are selectivity problems; meaning, if the impurities are removed at a high yield, there is also a significant loss of valuable metals [26,27]. Recently, ion exchange, an efficient impurity removal method, has been widely used in the purification of nickel containing solutions. Fernandez et al. [28] used the chelating resin (Amberlite IRC 718) to treat industrial waste leachate and found that the removal rate of $\mathrm{Zn}$ was $93 \%$ and the removal rate of $\mathrm{Cd}$ was $50 \%$. Chiu et al. [29] successfully tested several chelating resins (iminodiacetic acid, bispicolylamine, and phosphinic acid) for the adsorption of $\mathrm{Ni}$ and $\mathrm{Co}$ from manganese containing lithium-ion battery waste leachate. Zhang et al. [30] studied the removal of impurities in the synthetic lithium-ion battery waste leachate by ion exchange method through intermittent and column experiments. Ammonomethyl phosphonic acid functional chelating resin (Lewatit TP260) can remove $\mathrm{Fe}, \mathrm{Al}, \mathrm{Mn}$, and $\mathrm{Cu}$ from leachate while leaving a valuable pure mixture of $\mathrm{Co}, \mathrm{Ni}$, and $\mathrm{Li} .99 .6 \%$ pure $\mathrm{Li}+\mathrm{Co}+\mathrm{Ni}$ solution (battery grade) can be obtained by this process. Regarding the removal of magnesium in the solution, a chemical precipitation method is generally applied, such as adding sodium fluoride, or an extraction method can be also used to remove magnesium in the solution [31].

Table 4. The main chemical components in the leached solution.

\begin{tabular}{cccccccc}
\hline \multicolumn{2}{c}{ Chemical Component } & Ni & Mg & Fe & Cd & Al & Zn \\
\hline Conventional & Content (g/L) & 17.95 & 19.75 & 13.11 & 0.12 & 0.11 & $<0.1$ \\
Ultrasonic & Content (g/L) & 18.11 & 21.85 & 13.81 & 0.14 & 0.12 & $<0.1$ \\
\hline
\end{tabular}

\section{Conclusions}

(1) It is feasible to use sulfuric acid as leaching agent to recover nickel from the nickel containing residue.

(2) More than $95 \%$ nickel can be leached under the conditions of $600 \mathrm{~W}$ ultrasonic power, $15 \%$ sulfuric acid concentration, particle size of less than $150 \mu \mathrm{m}$, solid-liquid ratio of 1:7, leaching temperature of $25^{\circ} \mathrm{C}$, and leaching time of $40 \mathrm{~min}$. Under the above mentioned conditions, ultrasonic leaching can increase the Ni extraction degree from $58.26 \%$ to $95.50 \%$. The ultrasonic process increased the $\mathrm{Ni}$ extraction degree by about $63.92 \%$.

(3) Ultrasound wave greatly changes the microstructure of the leached residue particles. The particle boundary of the leached residue has obvious peeling trace, and the particle dispersion is better than that of the conventional conditions.

(4) The activation energies of the reaction under conventional and ultrasonic conditions were calculated as $E_{\mathrm{a} 1}=17.74 \mathrm{~kJ} / \mathrm{mol}$ and $E_{\mathrm{a} 2}=5.04 \mathrm{~kJ} / \mathrm{mol}$, respectively.

(5) The particle size of ultrasonic leaching residue is smaller than that of conventional leaching residue. And the specific surface area of the leached residue under ultrasonic conditions is $16.25 \%$ higher than that under conventional conditions. 
Author Contributions: F.L. and G.S. conceived and designed the experiments; Z.G. performed the experiments, analyzed the data, and wrote the initial draft of the manuscript; P.G. reviewed and contributed to the final manuscript. All authors have read and agreed to the published version of the manuscript.

Funding: This research was funded by the National Natural Science Foundation of China (Grant No. 51864042 and 51804220), the Youth Foundation of Natural Science Foundation of Henan Province (Grant No. 202300410100 and 212300410130), Key Scientific and Technological Project of Henan Province (Grant No. 192102310499, 212102310521 and 152102210306) and the High-level Talents Start-up Fund of Henan Institute of Technology (Grant No. KY1706 and KQ1820).

Institutional Review Board Statement: Not applicable.

Informed Consent Statement: Not applicable.

Data Availability Statement: Not applicable.

Conflicts of Interest: The authors declare no conflict of interest.

\section{References}

1. Gu, S.; Fu, B.; Ahn, J.W. Simultaneous removal of residual sulfate and heavy metals from spent electrolyte of lead-acid battery after precipitation and carbonation. Sustainability 2020, 12, 1263. [CrossRef]

2. Sundararaju, S.; Manjula, A.; Kumaravel, V.; Muneeswaran, T.; Vennila, T. Biosorption of nickel ions using fungal biomass Penicillium sp. MRF1 for the treatment of nickel electroplating industrial effluent. Biomass Convers. Biorefin. 2020, 6, 1-10. [CrossRef]

3. Jerroumi, S.; Lakhouiri, A.; Lekhlif, B.; Lakhdar, M.; Afrine, L.; Azzi, M.; Ngala Nsakou, S. Study of nickel removal from an electroplating unit wastewater by soda and characterization of the precipitate. J. Environ. Eng. Sci. 2018, 4, 321-327.

4. Sivakumar, D.; Nouri, J.; Modhini, T.M.; Deepalakshmi, K. Nickel removal from electroplating industry wastewater: A bamboo activated carbon. Glob. J. Environ. Sci. Manag. 2018, 4, 325-338.

5. Roy, A.; Stegemann, J.A. Nickel speciation in cement-stabilized/solidified metal treatment filtercakes. J. Hazard. Mater. 2016, 321, 353-361. [CrossRef] [PubMed]

6. Harper, G.; Sommerville, R.; Kendrick, E.; Driscoll, P.L.; Slater, R.; Stolkin, A.; Walton, P.; Christensen, O.; Heidrich, S.; Lambert, A.; et al. Anderson Recycling lithium-ion batteries from electric vehicles. Nature 2019, 575, 75-86. [CrossRef]

7. Lei, X.; Li, Y.; Weng, C.; Liu, Y.; Hu, J.; Yang, C.; Lin, Z.; Liu, M. Construction of heterostructured $\mathrm{NiFe}_{2} \mathrm{O}_{4}-\mathrm{C}$ nanorods by transition metal recycling from simulated electroplating sludge leaching solution for high performance lithium ion batteries. Nanoscale 2020, 12, 13398-13406. [CrossRef] [PubMed]

8. Weng, C.; Sun, X.; Han, B.; Ye, X.; Zhong, Z.; Li, W.; Liu, W.; Deng, H.; Li, Z. Targeted conversion of Ni in electroplating sludge to nickel ferrite nanomaterial with stable lithium storage performance. J. Hazard. Mater. 2020, 393, 122296. [CrossRef]

9. Peng, G.; Deng, S.; Liu, F.; Li, T.; Yu, G. Superhigh adsorption of nickel from electroplating wastewater by raw and calcined electroplating sludge waste. J. Clean. Prod. 2019, 246, 118948. [CrossRef]

10. Silva, J.E.; Soares, D.; Paiva, A.P.; Labrincha, J.A.; Castro, F. Leaching behaviour of a galvanic sludge in sulphuric acid and ammoniacal media. J. Hazard. Mater. 2005, 121, 195-202. [CrossRef] [PubMed]

11. Su, R.; Liang, B.; Guan, J. Leaching effects of metal from electroplating sludge under phosphate participation in hydrochloric acid medium. Procedia Environ. Sci. 2016, 31, 361-365. [CrossRef]

12. Zhang, P.; Sun, L.; Wang, H.; Cui, J.; Hao, J. Surfactant-assistant atmospheric acid leaching of laterite ore for the improvement of leaching efficiency of nickel and cobalt. J. Clean. Prod. 2019, 228, 1-7. [CrossRef]

13. Yang, C.; Li, S. Kinetics of iron removal from quartz under ultrasound-assisted leaching. High Temp. Mater. Process. 2020, 39, 395-404. [CrossRef]

14. Xi, F.; Cui, H.; Zhang, Z.; Yang, Z.; Li, S.; Ma, W.; Wei, K.; Chen, Z.; Lei, Y.; Wu, J. Novel and efficient purification of silicon through ultrasonic-cu catalyzed chemical leaching. Ultrason. Sonochem. 2019, 56, 474-480. [CrossRef]

15. Guo, P.; Wang, S.; Zhang, L. Selective removal of antimony from refractory gold ores by ultrasound. Hydrometallurgy 2019, 190, 105161. [CrossRef]

16. Zhang, Y.; Chen, X.; Chu, W.; Cui, H.; Wang, M. Removal of vanadium from petroleum coke by microwave and ultrasonic-assisted leaching. Hydrometallurgy 2020, 191, 105168. [CrossRef]

17. Li, H.; Zhang, L.; Xie, H.; Peng, J.; Li, S.; Yang, K.; Zhu, F. Ultrasound-assisted silver leaching process for cleaner production. JOM 2019, 72, 766-773. [CrossRef]

18. Zhang, K.; Li, B.; Wu, Y.; Wang, W.; Li, R.; Zhang, Y.; Zuo, T. Recycling of indium from waste LCD: A promising non-crushing leaching with the aid of ultrasonic wave. Waste Manag. 2017, 64, 236-243. [CrossRef] [PubMed]

19. Xie, H.; Li, S.; Zhang, L.; Wang, Y. Roasting pretreatment combined with ultrasonic enhanced leaching lead from electrolytic manganese anode mud. Metals 2019, 9, 601. [CrossRef] 
20. Nivetha, E.S.; Saravanathamizhan, R. Recovery of nickel from spent NiCd batteries by regular and ultrasonic leaching followed by electrodeposition. J. Electrochem. Sci. Eng. 2019, 10, 41-47. [CrossRef]

21. Gui, H.; Khan, M.; Wang, S.; Zhang, L. The ultrasound leaching kinetics of gold in the thiosulfate leaching process catalysed by cobalt ammonia. Hydrometallurgy 2020, 196, 105426. [CrossRef]

22. Guo, Z.; Guo, P.; Su, G.; Zhai, D.; Chen, F.; Li, F. High-Temperature Permittivity and Microwave Pretreatment Characteristics of Nickel-Containing Sludge from Battery Production. Processes 2019, 7, 257. [CrossRef]

23. Guo, Z.; Li, F.; Su, G.; Zhai, D.; Liu, C. Microwave drying of nickel-containing residue: Dielectric properties, kinetics, and energy aspects. Green Process. Synth. 2019, 8, 814-824. [CrossRef]

24. Dickinson, C.F.; Heal, G.R. Solid-liquid diffusion controlled rate equations. Thermochim. Acta 1999, 340, 89-103. [CrossRef]

25. Meshram, P.; Mishra, A.; Abhilash, R.; Sahu, R. Environmental impact of spent lithium ion batteries and green recycling perspectives by organic acids-A review. Chemosphere 2020, 242, 125291. [CrossRef]

26. Peng, C.; Chang, C.; Wang, Z.; Wilson, B.P.; Liu, F.; Lundström, M. Recovery of high-purity $\mathrm{MnO}_{2}$ from the acid leaching solution of spent Li-ion batteries. JOM 2020, 72, 790-799. [CrossRef]

27. Xiao, J.; Li, J.; Xu, Z. Challenges to future development of spent Lithium ion batteries recovery from environmental and technological perspectives. Environ. Sci. Technol. 2020, 54, 9-25. [CrossRef] [PubMed]

28. Fernández, Y.; MarañónL, E.; Castrillón, L.; Vázquez, I. Removal of Cd and Zn from inorganic industrial waste leachate by ion exchange. J. Hazard. Mater. 2005, 126, 169-175. [CrossRef] [PubMed]

29. Chiu, K.; Chen, W. Recovery and separation of valuable metals from cathode materials of spent lithium-ion batteries (LIBs) by ion exchange. Sci. Adv. Mater. 2017, 9, 2155-2160. [CrossRef]

30. Virolainen, S.; Wesselborg, T.; Kaukinen, A.; Tuomo, S. Removal of iron, aluminium, manganese and copper from leach solutions of lithium-ion battery waste using ion exchange. Hydrometallurgy 2021, 202, 105602. [CrossRef]

31. Li, Z.; Mercken, J.; Li, X.; Sofía, R. Efficient and sustainable removal of magnesium from brines for lithium/magnesium separation using binary extractants. ACS Sustain. Chem. Eng. 2019, 10, 19225-19234. [CrossRef] 